\title{
Epidemiological surveillance of employees in a mercury thermometer plant: An occupational health study
}

\begin{abstract}
A cross-sectional epidemiological survey of 255 individuals (130 current permanent employees, 64 contract workers, 55 ex-employees and 6 scrap dealers) coupled with a retrospective cohort study of the occupational health of 290 employees (all permanent employees who ever worked in the factory over a span of 15 years) was conducted in a mercury thermometer plant at Kodaikanal in India. The cross-sectional study done in March 2001 was based on a clinical protocol developed by the US Dept. of Labor, Mines Safety and Health Administration and was supplemented by the analysis of mercury in urine $(\mathrm{HgU})$ through Inductively Coupled Plasma Emission Spectrometry (ICP) and relevant biochemical investigations. Group averages of $\mathrm{HgU}$ in this study was $23.8 \mu \mathrm{g} / \mathrm{L}$ and were well within WHO-recommended limits of group means $(50 \mu \mathrm{g} / \mathrm{L})$. Group analysis was supplemented by appropriate individual analysis. The retrospective cohort study (for the years 1988-2001) included clinical evaluation coupled with analysis of biological monitoring done through Cold Vapor Atomic Absorption Spectrometry (CVAAS). Group averages of mercury in urine measured between 12.9 to $31.9 \mu \mathrm{g} / \mathrm{L}$ over the working life of the factory, and they too were supplemented by appropriate individual analysis. The protocol for epidemiological surveillance and indeed for the occupational health surveillance conducted over the life of the factory (biological monitoring, workplace environmental monitoring, shop floor health and safety practices and clinical evaluations) have been independently validated by the Netherlands-based TNO, the All India Institute of Medical Sciences, and the Indian Association of Occupational Health. None of the employees in this factory were found to be suffering from any ill health that could be attributed to $\mathrm{Hg}$ exposure.
\end{abstract}

Key words: Biological monitoring, cohort, environmental monitoring, epidemiological surveillance, mercury

\section{INTRODUCTION}

The current study deals with the epidemiological health surveillance of employees in a thermometer plant at Kodaikanal in India. The study combines a cross-sectional epidemiological survey supplemented with a retrospective cohort study and was undertaken to allay apprehension from the local communities in Kodaikanal on the health impact of the factory operations.

The Kodaikanal plant was set up in 1984 by Ponds India Ltd. with equipment from the USA. The unit got merged with Hindustan Lever Limited (HLL) in 1998. It was one of the largest manufacturers of thermometers in the world with an annual capacity of 20 million thermometers. The unit was certified to EN 46002 standards.

The factory was set up in Kodaikanal (under an industrial licence) since the ambient temperature there (Kodaikanal is at an altitude of 2120 $\mathrm{m}$ above sea level), which varied between 2 and $20^{\circ} \mathrm{C}$, would be conducive to negligible mercury vaporization. The factory, which was set up to US standards, had the following occupational health and safety measures in place.

Indoor air monitoring and regulation: The plant was divided into nonmercury and mercury areas, which were physically separated by walls. The non-mercury area was the place where glass-forming operations were carried out before mercury was filled into the thermometers. The mercury area was the place where all operations like mercury filling, top chambering, contracting, scaling, grading to final packing of the thermometers took place. The plant also ran a glass crushing and mercury recovery unit to recover mercury from the scrap glass generated during
T. Rajgopal, H. V. Ravimohan ${ }^{1}$, P. Mascarenhas ${ }^{2}$ Vice President, Medical and Occupational Health, ${ }^{1}$ Medical Officer, ${ }^{2}$ Area Medical Officer (South), Hindustan Lever Limited, India

For correspondence: T. Rajgopal, Vice President, Medical and Occupational Health, Hindustan Lever Limited, India.

E-mail:

thirumalai.rajgopal@Unile ver.com

This paper has been presented at XXXIInd International Congress of MEDICHEM

(Occupational and Environmental Health in the production and use of chemicals) held at Paris $1^{\text {st }}-3^{\text {rd }}$

September 2004 in session N 11B on Epidemiology.

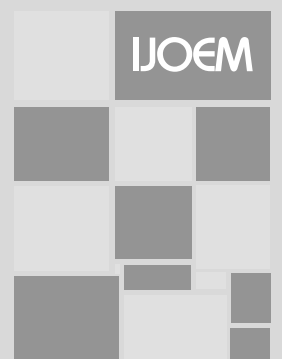


manufacturing operation. The plant used a gold film mercury vapor analyser (Jerome 431 X Mercury Vapor Analyzer) with a self-calibrating facility to monitor air from 22 locations spread across these areas in the non-mercury and mercury areas. This analyzer is considered quite sensitive to monitor $\mathrm{Hg}$ vapor, with a sensitivity of detecting $\mathrm{Hg}$ in air upto 0.003 $\mathrm{mg} / \mathrm{m}^{3} \cdot{ }^{[1]}$ The intention was to regulate mercury in the atmosphere to less than $0.05 \mathrm{mg} / \mathrm{m}^{3}$ of air by adopting the following methods:

- The main manufacturing area had a dimension of $60^{\prime} \mathrm{x}$ $100^{\prime}$ with a ceiling height of $12^{\prime}$. A total of 25 exhaust fans fitted along the southeastern wall of the mercury area turned over the air in this area every $45 \mathrm{~min}$ for $16 \mathrm{~h} /$ day for all the operating days in a year. Similarly the mercury crusher building and the mercury distillation building also had adequate exhaust fans that would turn over the air in that area at a greater frequency (every $5 \mathrm{~min}$ ). The flooring of the workplace was a cemented one.

- Vacuum cleaners with water seals were used to collect broken thermometers when breakage occurred. The factory floor was scrubbed and washed once a day with water to remove traces of mercury for further treatment at the effluent treatment plant.

- Operators in the mercury area of the plant were provided with special safety masks to filter out mercury vapors.

- All the above procedures were backed by an emergency procedure of opening all windows and cleaning the entire floor when mercury vapors exceeded $0.05 \mathrm{mg} / \mathrm{m}^{3}$.

\section{Occupational health surveillance}

All employees underwent a monthly monitoring of mercury in urine through the use of a Cold Vapor Atomic Absorption Spectrometer (CVAAS). Employees whose urine mercury level exceeded $100 \mu \mathrm{g} / \mathrm{L}$ were deployed out of the mercury area and in all such cases, the mercury levels came back to acceptable levels within 1-2 months. Such employees were very rare during the working life of the plant $(\sim 1 \%)$. The biological monitoring was supplemented by an annual clinical evaluation with specific emphasis on the oral cavity, skin, kidneys, the central nervous system and the cardiopulmonary system. The medical tests included a hemogram and a urine examination for albumin, red blood cells, casts and crystals.

Over the years, the factory has been subject to statutory inspections and health evaluations by the factory inspectorate of the government, who did not find any mercury-related illness amongst the employees.

\section{MATERIALS AND METHODS}

\section{Health impact assessment}

The health impact assessment used a combination of a crosssectional epidemiological survey supplemented with a retrospective cohort study. The health impact assessment has been conducted in accordance with guidelines on studies in environmental epidemiology. ${ }^{[2]}$ The design of the study allowed an assessment of both current and historical exposures and outcome. Exposure assessment in both designs looked at environmental monitoring data coupled with results of biological monitoring. For biological monitoring, we used urinary mercury concentrations $(\mathrm{HgU})$ as an appropriate biomarker. In risk assessment, biomarkers may be used in hazard identification, exposure assessment and to associate a response with the probability of a disease outcome.$^{[3]}$ Clinical evaluations utilized a combination of an administered questionnaire as well as appropriate clinical tests including relevant biochemical investigations.

\section{Cross-sectional epidemiological survey}

In the year 2001, following apprehension from the local communities at Kodaikanal on the health and environmental impact of the factory operations, HLL conducted a comprehensive epidemiological surveillance covering 255 individuals (130 current permanent employees, 64 contract workers, 55 ex-employees and 6 scrap dealers). The exemployees were those who responded to a newspaper advertisement inviting ex-employees to participate in the study. The clinical surveillance included the following:

A questionnaire modified on the one developed by the US Department of Labor, Mines, Safety and Health Administration for medical surveillance and biological monitoring for miners exposed to Arsenic, Cadmium, Lead and Mercury (technically reviewed by Center for Disease Control and Prevention - CDC, USA and the NIOSH, USA). An epidemiologist (trained at the London School of Hygiene) independently validated at site, the clinical evaluation based on the questionnaire.

The clinical evaluation included a thorough evaluation of the oral cavity, lungs, cardiovascular system, the eyes, skin, kidneys and the central nervous system. With specific reference to the central nervous system, the sensorimotor performance was evaluated using reflex evaluation, grip strength, handwriting analysis and vibration sense $(128 \mathrm{~Hz}$ at index finger/great toe). Psychomotor tests included handeye coordination, visual fields and color discrimination tests, memory evaluation and gait test.

The clinical surveillance was supplemented by biological monitoring through the analysis of mercury in urine by Inductively Coupled Plasma Emission Spectrometer (ICP). The ICP method for detection of mercury in urine is sensitive, with detection limits in the sub-ppb range. ${ }^{[4,5]}$ The laboratory performing the ICP was a government approved one and followed appropriate internal and external quality control measures.

Other investigations included the analysis of blood for 
hemoglobin, total and differential counts, urine analysis for albumin and sugar as well as the estimation of blood urea and serum creatinine as markers for kidney functions.

A team of local doctors from Kodaikanal who were appropriately trained to ensure that there was no inter- and intra-observer variability administered the questionnaire and conducted the clinical evaluation. Each individual undergoing the evaluation gave his informed consent. Since the local community had expressed apprehension vis-a-vis the health of ex-employees of the thermometer plant, the communitydesignated doctor was invited, who participated in the validation of the clinical evaluation.

The employees at the time of the survey $(n=130)$ underwent a repeat biological monitoring for mercury in urine in May 2001 post the closure of the factory. The factory closure was on the cards since thermometer manufacture did not fit in with the core business of Hindustan Lever Limited (detergents, skin care and foods business), and the company decided to exit from the thermometer business

\section{Retrospective cohort analysis}

To ascertain the impact of the factory operations on the health of all its employees, a retrospective cohort study of the health of all permanent employees who worked there from 1984 (a total of 290 employees over the working life of the plant) was undertaken. The retrospective study analyzed all available biological monitoring results of $\mathrm{HgU}$, which was conducted over the years through CVAAS, annual clinical evaluations, morbidity and mortality data. The CVAAS as a method to monitor HgU levels is considered to be sensitive and reliable and may be used on either digested or undigested samples. ${ }^{[6,7]}$ The CVAAS underwent a daily quality control through calibration using standard strength solutions.

In terms of the toxicokinetics of mercury, it is believed that mercury has a half-life in the urine for about 40-90 days. . $^{[8,9]}$ These results reflect the existence of compartments with elimination half-lives of about 2-3 months, presumably in the kidney. WHO also recommends the determination of mercury in urine by the use of AAS as a way to monitor exposure to mercury vapors. ${ }^{[10]}$

For the purpose of retrospective analysis, the individual and group historic exposure assessment was based on the biological monitoring results gathered from a total of 17,687 urinary mercury measurements by CVAAS. These analyses were based on the results of samples collected from employees, usually on a monthly basis at the beginning of the shift, throughout the working life of the plant.

On-site validation of the CVAAS methodology, calibration and quality control measures in place, was carried out by a team of specialists nominated by the Indian Association of Occupational Health, who observed and interviewed the operator responsible for conducting the analysis.

The retrospective analysis compared the results arising out of biological monitoring and clinical analyses for two distinct groups:, those working in the hazardous section within the plant and those working in the non-hazardous section within the plant. It also included a sickness absenteeism review.

The findings of the biological monitoring and clinical evaluation results were also compared with reports by other investigators on the health effects arising out of exposure to mercury and the available evidence on the threshold limits for exposure resulting in various health effects.

To augment our efforts in ascertaining if there were any health-related effects arising out of working in the factory, our medical officer wrote to leading medical professionals in Kodiakanal outlining our Occupational Health Surveillance Measures in place as well as seeking information from them on any employee who may have reported to them with symptoms attributable to mercury exposure. In addition, we conducted a hospital-based search for any admissions arising out of mercury-related symptoms in the hospitals of Kodaikanal. Data pertaining to mortality of employees was also analyzed with respect to exposure patterns, duration of service and cause of death (wherever available).

Historical exposure levels to mercury in the plant environment were analyzed from the environmental monitoring data records of air sampling (conducted over the years using a Jerome analyzer) covering the period 1988 to 2001.

\section{External peer reviews and validation}

At the request of the local community in Kodai, an ecotoxicological and health expert from TNO, Netherlands, reviewed the health and safety measures as well the impact of the factory operations on health and environment. He visited the site on a number of occasions and evaluated onsite health and safety measures and reviewed the health surveillance protocol including biological monitoring.

The protocol for clinical evaluation and the entire epidemiological surveillance was also independently reviewed by a team of experts from the All India Institute of Medical Sciences, Delhi (one of the premier medical institutes in the country).

In addition, an expert committee set up by the Indian Association of Occupational Health (IAOH) visited the site for an on-the-spot assessment, interviewed and validated the methodology of CVAAS analysis for Hg in urine and reviewed all health records and details of epidemiological surveillance 
conducted over the life of the plant.

\section{RESULTS}

\section{Cross-sectional epidemiological survey}

The following tables detail the general information, symptomatology and clinical evaluation results pertaining to the 255 individuals who participated in the cross-sectional epidemiological survey conducted in March 2001 (Tables 14).

We analyzed the symptomatology (grouped by systems) in relation to the results of biological monitoring.

We conducted a repeat biological monitoring in May 2001 for all 130 employees who underwent the occupational health surveillance in March 2001. As compared to a mean $\mathrm{HgU}$ value of $23.1 \mu \mathrm{g} / \mathrm{L}$ for these employees in March 2001, these values had dropped to a mean of $10.1 \mu \mathrm{g} / \mathrm{L}$ in May 2001. (The factory was closed down in April 2001.) The WHO recommends group means of $50 \mu \mathrm{g} / \mathrm{L}$ to prevent health-based effects. ${ }^{[11]}$

\section{Retrospective cohort study}

Group analyses: To understand the overall body burden of mercury over the working period of all employees, a total of 17,687 individual urinary mercury measurements (by CVAAS) gathered over the working life of the plant were analyzed.

As a first cut measurement, the group $\mathrm{HgU}$ means of all employees were tabulated from the year 1988 to 2001 to have an idea about overall exposures (Table 5). This first cut measurement was to have an idea vis-a-vis comparing them with WHO-recommended group means of $\mathrm{HgU}$ of $50 \mu \mathrm{g} / \mathrm{L}$ to prevent health-based effects. ${ }^{[11]}$

Employees were then grouped and analyzed according to the departments in which they worked. Broadly they were categorized into two groups: those working in the hazardous section of the mercury plant (filling, distillation and crusher units) and those working in the rest of the plant.

Biological monitoring data for these groups were analyzed on a three-year cumulative basis. The following table profiles the three-year HgU levels to give an idea about the cumulative body burden for these three-year periods (Table 6).

To understand individual variations, we undertook an analysis

Table 2: Details of clinical evaluation (general findings)

\begin{tabular}{lccccc}
\hline Morbidity & \multicolumn{2}{c}{$\begin{array}{c}\text { Permanent employees } \\
\text { (N=185) }\end{array}$} & & \multicolumn{2}{c}{$\begin{array}{c}\text { Others } \\
\text { (N=70) }\end{array}$} \\
\cline { 2 - 3 } \cline { 5 - 6 } & Number & $\%$ & & Number & $\%$ \\
\hline Inflammation of gum & 19 & 10.2 & & 5 & 7.1 \\
Stomatitis & 0 & 0 & & 0 & 0 \\
Dental Caries & 62 & 33.5 & & 25 & 35.7 \\
Hypertension & 13 & 7 & & 3 & 4.2 \\
Diabetes & 1 & 0.5 & & 3 & 4.2 \\
Asthma & 4 & 2 & & 2 & 2.8 \\
Hyperkeratosis & 0 & 0 & & 0 & 0 \\
Visual Disturbances & 0 & 0 & & 0 & 0 \\
Sensory neural disorders & 0 & 0 & & 0 & 0 \\
Lack of coordination & 0 & 0 & & 0 & 0 \\
Tremors & 3 & 1.6 & & 1 & 1.42 \\
Tuberculosis & 2 & 1 & & 1 & 1.42 \\
Seizures & 2 & 1 & & 0 & 0 \\
IHD & 1 & 0.54 & & 2 & 2.8 \\
Tumors (Pituitary adenoma) & 1 & 0.54 & & 0 & 0 \\
Ureteric Stone & 1 & 0.54 & & 0 & 0 \\
\hline
\end{tabular}

Table 3: Prevalence of various symptoms amongst surveyed individuals

\begin{tabular}{lccccc}
\hline & \multicolumn{2}{c}{ Permanent employees } & & \multicolumn{2}{c}{ Others } \\
\cline { 2 - 3 } \cline { 5 - 6 } & Number & $\%$ & & Number & $\%$ \\
\hline Fatigue & 18 & 9.7 & & 1 & 1.42 \\
Irritability & 5 & 2.7 & & 1 & 1.42 \\
Memory Disturbance & 5 & 2.7 & & 0 & 0 \\
Concentration lapse & 3 & 1.62 & & 0 \\
Insomnia & 14 & 7.5 & & 1 & 1.42 \\
Headaches & 7 & 3.7 & & 1 & 1.42 \\
Tingling and numbness in feet & 2 & 1.08 & & 1 & 1.42 \\
Reduced Coordination & 0 & 0 & & 0 & 0 \\
Shortness of breath & 10 & 5.4 & & 2 & 2.85 \\
Tightness of chest & 5 & 2.7 & & 0 & 0 \\
Indigestion & 11 & 5.9 & & 4 & 5.7 \\
\hline
\end{tabular}

Table 4: Symptoms in relation to $\mathrm{HgU}$ levels

\begin{tabular}{|c|c|c|c|c|c|c|}
\hline \multirow{2}{*}{$\begin{array}{l}\text { Symptoms } \\
\text { pertaining to }\end{array}$} & \multicolumn{5}{|c|}{ Biological monitoring results $-\mathrm{HgU}(\mu \mathrm{g} / \mathrm{L})$} & \multirow[t]{2}{*}{ Total } \\
\hline & $<20$ & $21-30$ & $31-40$ & $41-50$ & $>51$ & \\
\hline $\begin{array}{l}\text { Central Nervous } \\
\text { system }\end{array}$ & 34 & 49 & 1 & 1 & 3 & 78 \\
\hline Cardiovascular & 11 & 18 & 0 & 0 & 0 & 29 \\
\hline Respiratory & 20 & 44 & 0 & 1 & 0 & 65 \\
\hline Gastrointestinal & 4 & 12 & 0 & 0 & 0 & 16 \\
\hline Genitourinary & 2 & 4 & 0 & 1 & 0 & 7 \\
\hline
\end{tabular}

Table 1: General information

\begin{tabular}{|c|c|c|c|c|}
\hline \multirow[t]{2}{*}{ Parameters } & \multicolumn{2}{|c|}{ Permanent employees $\phi(N=185)$} & \multicolumn{2}{|c|}{ Others $\sigma(N=70)$} \\
\hline & Mean土S. D. & Range & Mean土S. D. & Range \\
\hline Age & $34.1 \pm 8.2$ & $18-50$ & $33.1 \pm 10.1$ & $18-58$ \\
\hline Weight $(\mathrm{kg})$ & $56.7 \pm 9.9$ & $35-92$ & $59.7 \pm 11.4$ & $41-102$ \\
\hline Height I (cm) & $162.1 \pm 7.9$ & $138-180$ & $164.3 \pm 8.9$ & 143-185 \\
\hline Years of service & $6.4+5.8$ & $0.2-18$ & $4.7 \pm 6$ & $0.2-22$ \\
\hline Urine mercury $[\mathrm{HgU}](\mu \mathrm{g} / \mathrm{L})^{*}$ & $23.9 \pm 5.9$ & $11.5-42.5$ & $23.6 \pm 5.2$ & $17.2-56.2$ \\
\hline
\end{tabular}

фPermanent employees included 130 current and 55 ex-employees, ${ }^{\circ}$ Others included contract employees (contract employees and those in gardening, security, administration and scrap dealers) *There is no statistical difference between the two groups with respect to age, weight, height and $\mathrm{HgU}$ levels 
Table 5: HgU means of all permanent employees in Kodaikanal plant

\begin{tabular}{ccc}
\hline Year & Number of employees & $\begin{array}{c}\text { Group HgU Values } \\
(\mu \mathrm{g} / \mathbf{L}) \text { Mean } \mathbf{+ S D}\end{array}$ \\
\hline 1988 & 208 & $22.7 \pm 10.4$ \\
1989 & 182 & $16.4 \pm 9.1$ \\
1990 & 147 & $26.4 \pm 16.5$ \\
1991 & 143 & $31.9 \pm 23.7$ \\
1992 & 151 & $24.2 \pm 22.6$ \\
1993 & 161 & $22.6 \pm 6.5$ \\
1994 & 161 & $21.9 \pm 4.6$ \\
1995 & 149 & $26.1 \pm 14.1$ \\
1996 & 136 & $31.8 \pm 16.6$ \\
1997 & 131 & $26 \pm 11.1$ \\
1998 & 126 & $24.3 \pm 11.8$ \\
1999 & 130 & $21.3 \pm 11.0$ \\
2000 & 126 & $24.8 \pm 10.6$ \\
2001 & 130 & $12.9 \pm 5.5$ \\
\hline
\end{tabular}

of all the individual $\mathrm{HgU}$ readings and prepared a cumulative frequency chart to study the spread of risk across various body burdens of mercury as evidenced by $\mathrm{HgU}$ levels in employees over the years. As depicted in Table 7, categorizes the cumulative frequency with respect to four different risk profiles, i.e., those employees with a mean annual $\mathrm{HgU}$ value of $<50 \mu \mathrm{g} / \mathrm{L}$, those with $\mathrm{HgU}$ between 50 and $60 \mu \mathrm{g} / \mathrm{L}$, those with $\mathrm{HgU}$ between 60 and $70 \mu \mathrm{g} / \mathrm{L}$ and those with $\mathrm{HgU}$ of $>70$ $\mu \mathrm{g} / \mathrm{L}$.

Of particular interest were those employees with $>70 \mu \mathrm{g} / \mathrm{L}$ since they would have corresponded to an exposure of $\mathrm{Hg}$ in air of $>0.05 \mathrm{mg} / \mathrm{m}^{3}$. [In India the permissible limits of mercury in air are $0.05 \mathrm{mg} / \mathrm{m}^{3}\left(50 \mu \mathrm{g} / \mathrm{m}^{3}\right)^{\dagger}$ which correspond to an equivalent of $\mathrm{HgU}$ of $70 \mu \mathrm{g} / \mathrm{L}$.] (Equivalent values are based on guideline provided by WHO. $\left.{ }^{[12]}\right)$

Individuals with yearly means of $>70 \mu \mathrm{g} / \mathrm{L}$ (0-4\% during the years 1988 to 2001) were followed up to determine if any of them continued to show such values in subsequent years. There were no individuals who had two consecutive yearly means of $\mathrm{HgU}>70 \mu \mathrm{g} / \mathrm{L}$.

In view of community concerns that some employees may have died because of working in the thermometer plant as a consequence of exposure to mercury due to conditions like renal failure or CNS conditions, we undertook a mortality analysis of 10 employees who had worked with us and died
Table 7: Number of individuals under various categories of exposure as evidenced by biological monitoring results for the years 1988 to 2001.

\begin{tabular}{|c|c|c|c|c|c|}
\hline \multirow[t]{2}{*}{ Year } & \multicolumn{4}{|c|}{ Mercury in urine $(\mu \mathrm{g} / \mathrm{L})$} & \multirow[b]{2}{*}{ Total } \\
\hline & $<50 \mu \mathrm{g} / \mathrm{L}$ & 51-60 $\mu g / L$ & 61-70 $\mu \mathrm{g} / \mathrm{L}$ & $71+\mu g / L$ & \\
\hline 1988 & 201 & 6 & 0 & 1 & 208 \\
\hline 1989 & 179 & 3 & 0 & 0 & 182 \\
\hline 1990 & 142 & 1 & 2 & 2 & 147 \\
\hline 1991 & 129 & 2 & 6 & 6 & 143 \\
\hline 1992 & 138 & 5 & 2 & 6 & 151 \\
\hline 1993 & 160 & 0 & 1 & 0 & 161 \\
\hline 1994 & 161 & 0 & 0 & 0 & 161 \\
\hline 1995 & 145 & 0 & 1 & 3 & 149 \\
\hline 1996 & 119 & 8 & 3 & 6 & 136 \\
\hline 1997 & 125 & 4 & 1 & 1 & 131 \\
\hline 1998 & 120 & 3 & 2 & 1 & 126 \\
\hline 1999 & 124 & 5 & 0 & 1 & 130 \\
\hline 2000 & 121 & 4 & 1 & 0 & 126 \\
\hline 2001 & 130 & 0 & 0 & 0 & 130 \\
\hline
\end{tabular}

†Indian Factories Act 1948, Second Schedule.

either when in service or after leaving us. The results of this analysis are depicted in Table 8.

The exposure pattern of these individuals as evidenced by the analysis of $\mathrm{HgU}$ levels (wherever available) for these employees did not reveal any exposure of significance. There was also no correlation between the department they worked and mortality.

\section{Environment monitoring results}

Our retrospective analysis also reviewed historical exposure data as evidenced by levels of $\mathrm{Hg}$ in the atmosphere.

The Table 9 has been prepared based on the basis of monitoring at 15-23 locations across the factory on a daily basis for the years under consideration. The air monitoring data for the years 1994-1997 were not available for review. As seen in the table, the general average levels of mercury in atmosphere were much below the permissible limit (in India) of a time weighted average of $0.05 \mathrm{mg} / \mathrm{m}^{3} .^{\dagger}$

${ }^{\dagger}$ Indian Factories Act 1948, Second Schedule.

\section{DISCUSSION}

Chronic exposure to mercury could lead to kidney and neurological toxicity (especially tremor), inflammation of the

Table 6: Triennial urinary mercury levels (mean + SD) in permanent employees

\begin{tabular}{|c|c|c|c|c|c|}
\hline \multirow[t]{2}{*}{ Triennial period } & \multicolumn{2}{|c|}{ Hazardous section* $\mathrm{HgU}(\mu \mathrm{g} / \mathrm{L})$} & \multicolumn{2}{|c|}{ Non-hazardous section $\mathrm{HgU}(\mu \mathrm{g} / \mathrm{L})$} & \multirow[b]{2}{*}{ t value va $^{*}$} \\
\hline & $\mathbf{N}$ & Mean+S.D. & $\mathbf{N}$ & Mean+S.D. & \\
\hline 1988-1990 & 19 & $26+26$ & 161 & $21.5+23.2$ & 0.721 \\
\hline 1991-1993 & 19 & $30.1 \pm 29.5$ & 134 & $25.5+25.8$ & 0.645 \\
\hline 1994-1996 & 17 & $25.4+19.3$ & 131 & $25.9 \pm 19.6$ & -0.100 \\
\hline 1997-1999 & 13 & $27.4+20.2$ & 109 & $22.6 \pm 16$ & 0.826 \\
\hline $2000-2001$ & 13 & $26.8+20.4$ & 113 & $19.1 \pm 15.7$ & 1.316 \\
\hline Overall & 37 & $27.1 \pm 24.1$ & 253 & $23.2+21.0$ & 0.093 \\
\hline
\end{tabular}

${ }^{*}$ Hazardous section depicts the distillation, mercury filling and crusher sections. ${ }^{* *}$ t values are statistically insignificant indicating no difference between the two groups 
Rajgopal T, et al: Epidemiological surveillance of employees in a mercury thermometer plant

Table 8: Mortality analysis of employees who worked in the thermometer factory

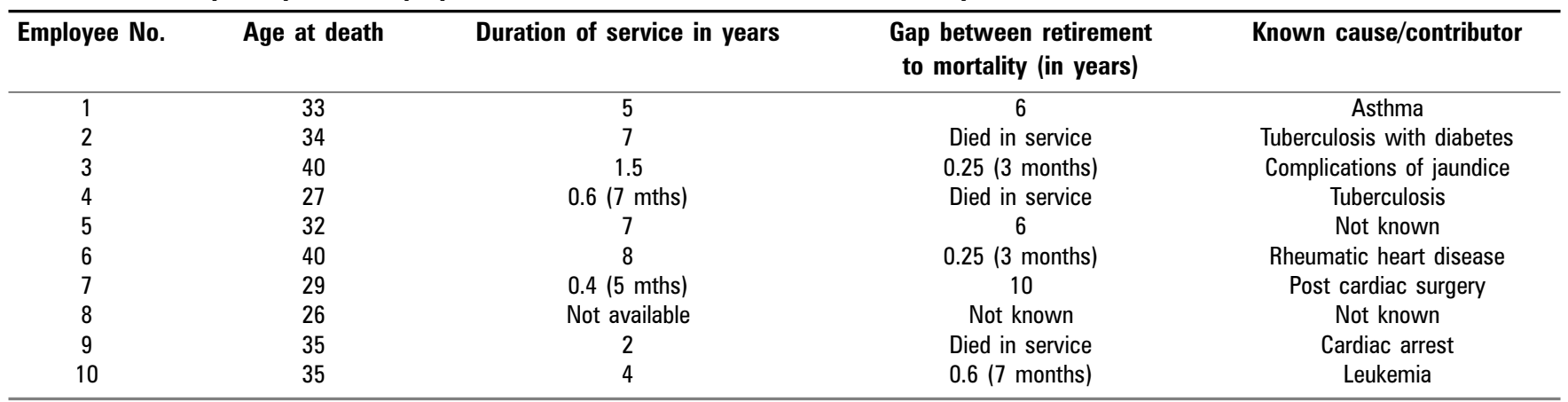

Table 9: Results (mean values) of air sampling in different sections of the thermometer plant $\left(\mathrm{mg} / \mathrm{m}^{3}\right)$

\begin{tabular}{|c|c|c|c|c|c|c|c|c|c|c|}
\hline Section & 1988 & 1989 & 1990 & 1991 & 1992 & 1993 & 1998 & 1999 & 2000 & 2001 \\
\hline Non-mercury & 0.013 & 0.016 & 0.015 & 0.034 & 0.043 & 0.017 & 0.022 & 0.023 & 0.006 & 0.003 \\
\hline Filling & 0.023 & 0.023 & 0.043 & 0.047 & 0.044 & 0.046 & 0.047 & 0.038 & 0.012 & 0.010 \\
\hline Top chamber & 0.010 & 0.016 & 0.021 & 0.031 & 0.047 & 0.029 & 0.039 & 0.034 & 0.006 & 0.005 \\
\hline Contracting & 0.016 & 0.015 & 0.020 & 0.028 & 0.021 & 0.034 & 0.033 & 0.037 & 0.009 & 0.006 \\
\hline Air pass & 0.017 & 0.016 & 0.017 & 0.028 & 0.041 & 0.040 & 0.035 & 0.039 & 0.009 & 0.010 \\
\hline Laser and inspection & 0.017 & 0.015 & 0.017 & 0.018 & 0.035 & 0.025 & 0.039 & 0.043 & 0.007 & 0.005 \\
\hline Grading & 0.013 & 0.014 & 0.014 & 0.018 & 0.003 & 0.001 & 0.027 & 0.025 & 0.004 & 0.003 \\
\hline Screen printing & 0.023 & 0.022 & 0.024 & 0.030 & 0.028 & 0.019 & 0.036 & 0.028 & 0.007 & 0.005 \\
\hline Head cutting & 0.017 & 0.015 & 0.014 & 0.022 & 0.029 & 0.024 & 0.041 & 0.042 & 0.008 & 0.006 \\
\hline Quality assurance & 0.014 & 0.012 & 0.011 & 0.018 & 0.023 & 0.009 & 0.019 & 0.025 & 0.006 & 0.005 \\
\hline Packing & - & - & - & 0.007 & 0.029 & 0.040 & 0.035 & 0.023 & 0.007 & 0.003 \\
\hline Distillation and crushing & - & - & 0.024 & 0.048 & 0.042 & 0.038 & 0.049 & 0.064 & 0.024 & 0.018 \\
\hline
\end{tabular}

gums, weakness, fatigue, insomnia, allergic skin rash, loss of appetite and impaired memory. ${ }^{[13]}$ Our questionnaire elicited response to these symptoms and morbidities.

A study by Roels et al. ${ }^{[14]}$ used a questionnaire mainly to elicit symptoms related to the central nervous system disturbances. Several symptoms, mainly related to the central nervous system (memory disturbances, depressive feelings, fatigue and irritability), were more prevalent in the exposed subjects rather than the controls. The symptoms were however not related to exposure parameters. The authors therefore considered it possible that the reporting of these symptoms were influenced by the knowledge of mercury vapor exposure. Exposure in the range of $25-80 \mu \mathrm{g} / \mathrm{m}^{3}$ increases incidence of symptoms like fatigue, irritability, loss of appetite. ${ }^{[15]}$

In our study (Tables 2, 3 and 4) also, the symptomatology did not have any significant correlation with the body burden of mercury (as HgU). Neither could we correlate any morbidity with exposure to $\mathrm{Hg}$ in view of very low levels of exposure, as evidenced by the results of the biological monitoring in these groups (Table 1). Three individuals with tremors were considered to be normal since their sample of handwriting taken at the time of the survey did not reveal any tremors.

We looked at some of the confounding factors, which could have caused common morbidity. For example in India, gingivitis is very common and is related to levels of poor oral hygiene. ${ }^{[16]}$

The main target organs for health-related effects arising out of long-term exposure to mercury are the brain and the kidneys.

In order to understand the relationship between exposure and health effects, we reviewed relevant studies, and the Table 10 summarizes key studies correlating the urinary threshold values in relationship to the effects on the nervous system or the kidney.

Rosemann et al. ${ }^{[26]}$ found positive correlation between $\mathrm{HgU}$ levels (100 $\mu \mathrm{g}-250 \mu \mathrm{g} / \mathrm{L})$ and neuropsychological symptoms. In a study conducted by Smith et al, ${ }^{[27]}$ short-term memory was affected in a group of individuals with a mean of $180 \mu \mathrm{g} /$ L.

Based on neuromuscular, electromyographic and psychomotor tests, Miller et al. ${ }^{[28]}$ recommended that when HgU exceeds $100 \mu \mathrm{g} / \mathrm{L}$, a person should be routinely examined to determine if any deterioration in the health status has taken place.

WHO $^{[10]}$ also recommends that symptom-free workers with a concentration of mercury in urine $>100 \mu \mathrm{g} / \mathrm{L}$ should also be kept away from exposure until the concentration drops to below that level. Langolf et al. ${ }^{[29]}$ found that the subclinical effects of mercury were mainly detectable in those workers 
Table 10: Summary of dose-effect relationships on $\mathrm{Hg}$ exposure with effects on the nervous system and the kidneys.

\begin{tabular}{|c|c|c|}
\hline Target organ & Threshold limit for $\mathrm{HgU}$ & Reference \\
\hline Nervous system and kidney & $\mathrm{HgU}$ of $>500 \mu \mathrm{g} / \mathrm{L}$ in the previous year & Langolf et al ${ }^{[17]}$ \\
\hline Nervous system - Impaired performance on visual memory tasks & $\mathrm{HgU}$ peaks $>100 \mu \mathrm{g} / \mathrm{L}$ & Forzi et al ${ }^{[18]}$ \\
\hline Nervous system-Abnormal reflexes, decreased coordination & $\mathrm{HgU}>600 \mu \mathrm{g} / \mathrm{L}$ & Albers et $a^{[19]}$ \\
\hline Kidneys (Excretion of high and low molecular weight proteins) & Biological permissible limit of $200 \mu \mathrm{g} / \mathrm{L}$ & Schaller et al[21] \\
\hline Kidneys (Glomerular type proteinuria) & $\mathrm{HgU}>50 \mu \mathrm{g} / \mathrm{g}$ creatinine & Berode et $\mathrm{al}^{[22]}$ Buchet et $\mathrm{al}^{[23]}$ \\
\hline Impaired performance in memory tasks & Group means $\mathrm{HgU} 56 \mu \mathrm{g} / \mathrm{L}$. & Piikivi et al ${ }^{[24]}$ \\
\hline
\end{tabular}

whose $\mathrm{HgU}$ had exceeded $500 \mu \mathrm{g} / \mathrm{L}$ in the previous year.

Tremor, abnormal Romberg test, dysdiadochokinosis and difficulty with heel-to-toe gait were observed in thermometer plant workers subjected to personal breathing zone concentrations of $0.078 \mathrm{mg} / \mathrm{m}^{3}{ }^{[30]}$

In order to prevent mercury-related ill health, the $\mathrm{WHO}^{[11]}$ recommends for workers a group mean of $\mathrm{HgU}$ of $50 \mu \mathrm{g} / \mathrm{L}$ as a health-based exposure limit. The results of the retrospective analyses has shown that employees in HLL had group HgU levels significantly lower than the recommended WHO limit (Tables 6 and 7). This could be due to historically low levels of exposure to $\mathrm{Hg}$ in the thermometer plant.

Several studies have shown a correlation between airborne mercury and mercury in urine ${ }_{i}$ but the results vary, and it is not clear if the ratio between such concentrations is constant at different exposure levels. ${ }^{[31]}$ Limiting the analysis to studies in which the exposure has been assessed using personal breathing zone mercury concentrations, it was estimated that in continuous 8h/day occupational exposure, an airborne mercury concentration of $1 \mathrm{mg} / \mathrm{m}^{3}$ leads to an average urinary mercury concentration of $1.4 \mathrm{mg} / \mathrm{L} \cdot{ }^{[12]}$

Using this derived relationship, the historical exposure of $\mathrm{Hg}$ in atmosphere to employees in the thermometer factory based on the biological monitoring results (Table 6) would be as shown in Table 11.

The current regulation in India as laid down by the Indian Factories Act prescribes a TLV of $0.05 \mathrm{mg} / \mathrm{m}^{3+}$ for $\mathrm{Hg}$ in the work environment. ${ }^{+}$Indian Factories Act 1948, Second Schedule. As indicated (Table 7), very few individuals had an exposure above these prescribed limits (based on the results of the biological monitoring), and even these few individuals (with a value of $\mathrm{HgU}$ of $>70 \mu \mathrm{g} / \mathrm{L}$ ) did not have a sustained exposure

Table 11: Showing the average exposure to mercury in the plant environment (cumulated for 1988-2001)

\begin{tabular}{lc}
\hline Department & Mean $\pm \mathbf{S}$. D. $\mathbf{H g}$ in atmosphere $\left(\mathbf{m g} / \mathbf{m}^{3}\right)$ \\
\hline Hazardous section & $0.019 \pm 0.017$ \\
Non-Hazardous section & $0.017 \pm 0.015$ \\
\hline
\end{tabular}

in subsequent years.

A review of the levels of $\mathrm{Hg}$ in different sections of the plant on the basis of monitoring at 15-23 locations across the factory on a daily basis indicates that levels in the plant were much lower than the prescribed limits in India (Table 9). Workplace safety and health measures contributed to minimizing significant exposures to $\mathrm{Hg}$.

\section{CONCLUSIONS}

On the basis of the results of environmental monitoring, biological monitoring, clinical evaluation and review in comparison to published data on dose-response relationships, there is no evidence to suggest that any of the employees in the thermometer plant suffered from health effects that could be attributed to mercury exposure. Analysis of the mortality data of 10 individuals (Table 8) who died either in service or after leaving employment has also not indicated any mortality that could be attributed to effects of mercury-related exposure. Community concerns have mainly been fanned by interested groups without any scientific evidence to substantiate claims of ill health amongst employees at the thermometer plant. ${ }^{[32]}$

The ecotoxicological and health expert from TNO who reviewed health and safety measures as well as the epidemiological surveillance at the request of the local communities and a peer review conducted by the All India Institute of Medical Sciences as well as the Indian Association of Occupational Health have all independently validated the occupational health and safety measures at the plant and their efficacy.

Over the years, the factory has been subject to statutory inspections and health evaluations by the factory inspectorate of the government, who did not find any mercury-related illness amongst the employees.

\section{ACKNOWLEDGMENTS}

The authors would like to acknowledge the expert inputs and validation report of various experts who reviewed the health data and validated the epidemiological surveillance and the 
results thereof. They include Dr. Tom Van Teunenbroek, formerly with TNO, Netherlands, and currently the team leader and advisor on international inspections with the ministry of VROM, Netherlands; Dr. Pandav and his team from the All India Institute of Medical Sciences; and the expert committee set up by the Indian Association of Occupational Health.

We are also thankful to Professor Dr. Prakash Kotecha from the Dept. of Community Medicine, Medical College, Vadodara, for validating the clinical evaluation on site.

Thanks are also due to Drs. Elamavazhuthi, Balasubramaniam, Saravanan and Ramesh Rao at Kodaikanal for participating in and conducting the clinical evaluation in March 2001.

\section{REFERENCES}

1. Chien YC, Fieldman CA, Zohn HK, Weisel CP. Urinary mercury levels before and after amalgam restoration. Science of the total environment 1996;188:39-47.

2. WHO. Environmental Health Criteria 27. Guidelines on studies in Environmental Epidemiology 1983.

3. WHO. International Programme on Chemical Safety Biomarkers and Risk Assessment: Concepts and Principles. Environmental Health Criteria 155. 1993.

4. Buneaux F, Buisine A, Bourdon S, Bourdon R. Continuous flow quantification of total mercury in whole blood, plasma, erythrocytes and urine by inductively coupled plasma atomic-emission spectroscopy. J Annal Toxicol 1992;16:99-101.

5. Kalamegham R, Ash KO. A simple ICP-MS procedure for the determination of total mercury in whole blood and urine. J Clin Lab Anal 1992;6:190-3.

6. Fries KH, Roschig M, Wienscher G. A new calibration method for the determination of trace amounts of mercury in air and biological methods. Fresenius J Anal Chem 1990;337:860-6.

7. Ping L, Dasgupta PK. Determination of urinary mercury with an automated microbatch analyzer. Anal Chem 1990;62:85-8.

8. Roels H, Boeckx M, Ceulemans E, Lauwerys R. Urinary excretion of mercury after occupational exposure to mercury vapour and influence of the chelating agent meso 2.3- dimercaptosuccinic acid (DMSA. Brit Jr Ind Med 1991;48:247-53.

9. Barregard L, Sallsten G, Schutz A, Attewell R, Skerfving S, Jarvholm B. Kinetics of mercury in blood and urine after brief exposure. Arch Environ Health 1992;47:176-84.

10. WHO. Early detection of occupational diseases. Diseases caused by mercury; 1986. p. 80.

11. WHO. Recommended Health-Based limits in occupational exposure to heavy metals. Report of a WHO study group. Technical report series $647 ; 1980$

12. WHO. International Programme on Chemical Safety. Concise international chemical assessment document 50. Elemental Mercury and Inorganic Mercury compounds: Human Health Aspects; 2003.

13. NIOSH. NIOSH/OSHA Occupational health guidelines for chemical hazards. Cincinnati. National Institute for Occupational Safety and
Health, DIHHS publication no. (NIOSH); 1981. p. 81-123.

14. Roels H, Gennart J-P, Lauwerys, R. Buchet, J-P. Surveillance of workers exposed to mercury vapour. Validation of a previously proposed biological threshold limit value for mercury concentration in urine. Am J Ind Med 1985;7:45-71.

15. WHO. International Programme on Chemical Safety. Inorganic mercury. Environmental Health Criteria 1991;118:110-111.

16. Bartold PM, Ishawawa I, Siravat M. Progress of Periodontal Research and Practice in Asian Pacific Countries. Asian Pacific Society of Perdontology; 2000. p. 81-2.

17. Langolf GD, Chaffin DB, Henderson R. Evaluation of workers exposed to elemental mercury using quantitative tests. Am. Ind.Hyg. Assoc J 1978;39:976-84.

18. Forzi M, Cassitto MG, Bulgheroni C, Foa V. Psychological measures in workers occupationally exposed to mercury vapor. A validation study. Adverse effects of environmental chemicals and psychotoxic drugs. Amsterdam, Oxford, New York, Elsevier Science Publishers; 1978. p. 165-72.

19. Albers JW, Kallenbach LR, Fine LJ. Neurological abnormalities associated with remote occupational elemental mercury exposure. Am Jr Ind Med 1988;15:517-29.

20. Roels H, AbdeladimM, Braun. Detection of hand tremors in workers exposed to mercury vapor. A comparative study of three methods. Environ Res 1989;49:152-65.

21. Schaller KH, Gonzales J, Thurauf J, Schiele R. Detection of early kidney damages in workers exposed to lead mercury and cadmium. Zentralbl Bakteriol Hyg. I Abt Orig B 1980;171:320-5.

22. Berode M, Guillemin MP, Martin B, Balant L. Evaluation of occupational exposure to metallic mercury and its early renal effects, In: Holmestedt B, Lauwerys R, Mercier M, Rolberfroid M, editors. Mechanisms of toxicity and hazard evaluation. Elsevier/North Holland: Biomedical Press, Amsterdam; 1980. p. 371-4.

23. Buchet JP, Roels H, Bernard, Lauwerys R. Assessment of renal function of workers exposed to inorganic lead, cadmium or mercury vapor. J. Occup Med 1980:22:741-50.

24. Piikivi L, Hamninen T, Maretelin. Psychological performance and long term exposure to mercury vapors. Scandi J Work Environ Health 1984;10:35-41.

25. Roels H, Lauwreys R, Buchet JP. Comparison of renal function and psychomotor performance in workers exposed to elemental mercury. Int Arch Occup Environ Health 1982;50:77-93.

26. Rosemann KD, Valciukas JA, Glickman L. Sensitive indicators of inorganic mercury toxicity. Arch Environ Health 1986;41:208-15.

27. Smith PJ, Langholf GD, Goldberg J. Effects of Occupational Exposure to elemental mercury on short-term memory. Br J Ind Med 1983;40:413-9.

28. Miller JM, Chaffin DB, Smith RG . Subclinical psychomotor and neuromuscular changes in workers exposed to inorganic mercury. Am Ind Hyg Assoc J 1975;36:725-33.

29. Langolf GD, Chaffin DB, Henderson R. Evaluation of workers exposed to elemental mercury using quantitative tests. Am Ind Hyg Assoc J 1978;39:976-84.

30. Ehrenberg RL, Vogt RL, Smith AB. Effects of elemental mercury exposure at a thermometer plant. American Jr Ind Med 1991;19:495507.

31. Smith RG, Vorwald AJ, Patil LS \& Mooney TF. Effects of exposure to mercury in the manufacture of chlorine. Ann Ind Hyg J 1970;31:681700.

32. Rajgopal T. Mercury pollution in India. The Lancet 2003;362:1856-7. 